\title{
Correction to: Which trophic discrimination factors fit the best? A combined dietary study of a coastal seabird
}

\author{
Annick Morgenthaler ${ }^{1}(\mathbb{C})$ Ana Millones ${ }^{1}(\mathbb{C}) \cdot$ Patricia Gandini $^{1,2} \cdot$ Esteban Frere $^{1,2}(\mathbb{C}$
}

Published online: 16 December 2020

(c) Deutsche Ornithologen-Gesellschaft e.V. 2020

\section{Correction to: Journal of Ornithology \\ https://doi.org/10.1007/s10336-020-01813-5}

In the original publication of the article, the Fig. 2 was published incorrectly. The original published Fig. 2 and its caption must be replaced by the Fig. 2 as given below:

The original article can be found online at https://doi.org/10.1007/ s10336-020-01813-5.

Annick Morgenthaler

amorgenthaler@uaco.unpa.edu.ar

1 Centro de Investigaciones de Puerto Deseado, Universidad Nacional de la Patagonia Austral, Av. Prefectura s/n, 9050 Puerto Deseado, Santa Cruz, Argentina

2 Consejo Nacional de Investigaciones Científicas y Técnicas (CONICET), Av. Prefectura s/n, Puerto Deseado 9050, Santa Cruz, Argentina
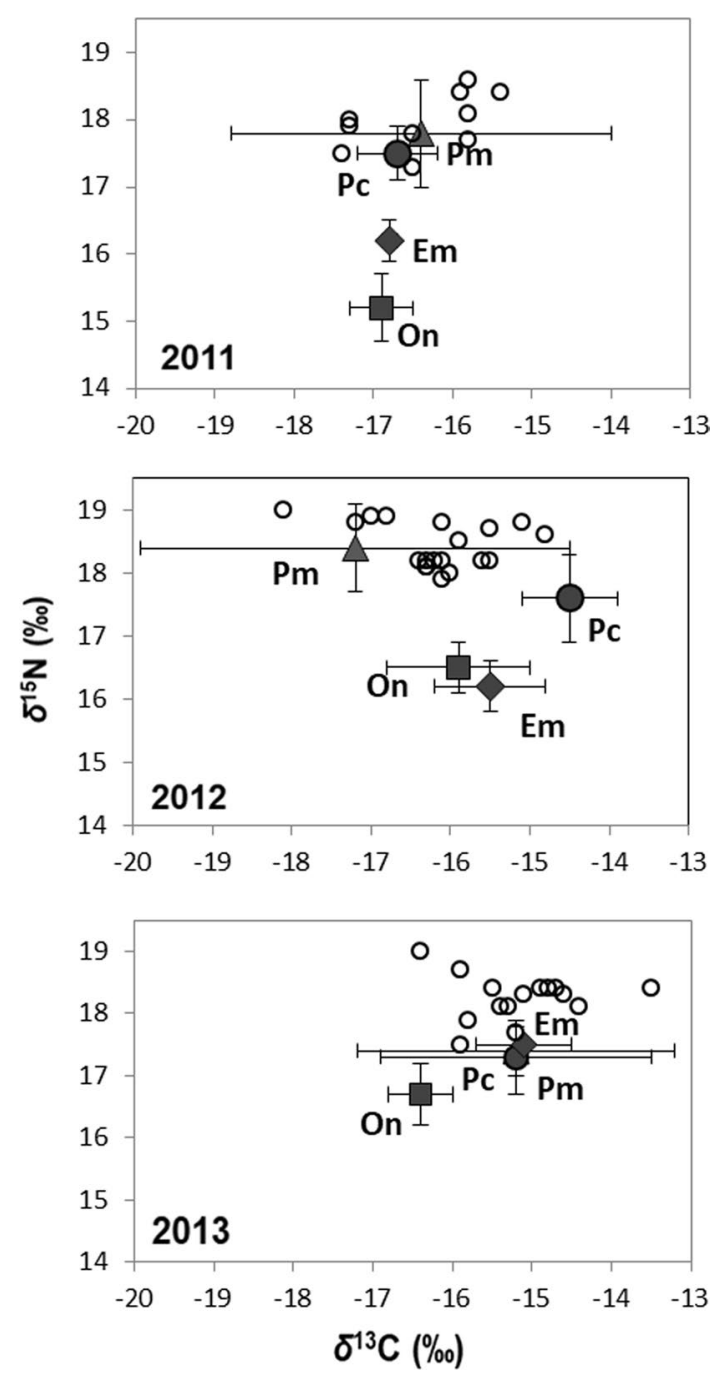

Fig. 2 Position of chick Neotropic cormorants (white circles) and main prey in the $\delta^{13} \mathrm{C}-\delta^{15} \mathrm{~N}$ bivariate space for each year. The values of prey correspond to those presented in Table 1 (mean \pm standard deviation), without adding any trophic discrimination factors. Prey are notothenioids fish species (rock cods/blenny): Pm, Paranotothenia magellanica; Pc, Patagonotothen cornucola; Em, Eleginops maclovinus and one atherinopsid (silverside); On, Odontesthes nigricans 
Publisher's Note Springer Nature remains neutral with regard to jurisdictional claims in published maps and institutional affiliations. 